\title{
Homecoming of soldiers who are citizens: Re-employment and financial status of returning Army National Guard soldiers from Operations Iraqi Freedom (OIF) and Enduring Freedom (OEF)
}

\author{
James Griffith \\ National Center for Veterans Studies and Psychology Faculty, St. Johns River State College, FL, USA \\ Tel.: +1 301452 6026; E-mail: jhgriffith@comcast.net
}

Received 1 November 2012

Accepted 6 May 2013

\begin{abstract}
This study examined civilian employment among Army National Guard soldiers who had recently returned from Operations Iraqi Freedom (OIF) and Enduring Freedom (OEF). Of specific interest were relationships of re-employment and financial difficulties to several conditions, such as amount of social support during and after deployment, combat exposure, negative feelings during and after deployment, and postdeployment adjustment symptoms. Survey data from the Army's Reintegration Unit Risk Inventory were used (4,546 soldiers in 50 units who were deployed during 2010). Few soldiers reported financial difficulties during deployment $(7.1 \%$ of the sample) and after having returned (11.8\%). Of those who reported postdeployment financial difficulties, nearly one-half had reported such difficulties during deployment, and not having resumed the predeployment job was associated with more postdeployment financial difficulties. Logistic regression analyses showed the relative contribution of the study variables to changed financial status, from deployment to postdeployment. Reported deployment support (e.g., trust in the unit chain-of-command and available support) was associated with decreased financial difficulties. In contrast, increased financial difficulties were associated with having seen others wounded or killed in combat. Other postdeployment experiences, such as feelings of anger and frustration and available support, were associated with increased financial difficulties, in addition to alcohol use, trouble sleeping and suicidal thoughts. Implications of results for policy and practice to lessen financial hardships and job loss associated with deployment are discussed.
\end{abstract}

Keywords: Army National Guard, homecoming, deployment, re-employment, financial status changes

\section{Background}

Reserve military service is unique. In the U.S. and other Western countries, this service has been, by and large, a part-time endeavor - serving intermittently in garrison units for one weekend a month and 15 days annual training a year. ${ }^{1}$ Reserve military service has

\footnotetext{
${ }^{1}$ This paper pertains to U.S. reserves, specifically, the Army National Guard, which when combined with the U.S. Army Reserve,
}

had much to do with world geopolitics and the role of reservists in national defense. After World War II, the U.S. had gained hegemony in world politics. Both the Soviet Union and the People's Republic of China

constitutes the Army reserve component, comprising as high as 30$40 \%$ of the ground forces in OIF and OEF. In total, the U.S. reserve force consists of seven components, one for each of the five services (Army, Navy, Marine Corps, Air Force, and Coast Guard), in addition to the Air and Army National Guard. 
presented perceived and real national security threats. These threats required a large military force to protect U.S. interests, but maintaining a large army was expensive [19]. A small standing Army, which would be complemented by reservists when needed, was seen as less costly and would serve as a reserve force when threats escalated [7]. Thus, the reserve component remained largely a strategic force, to be used for extraordinary circumstances. The deterrent strategy meant that reservists would not be called to active duty. Activation of reservists was viewed as a national strategy to deter Soviet aggression, to be employed cautiously so as not to provoke escalations from the Soviets, potentially leading a nuclear exchange [7]. The result was that few reservists expected to be called up to serve beyond a part-time basis, short of a nuclear Armageddon [11]. This service has had relatively low demands, compared to present day reserve military service.

\section{Changed role of the reserve force}

This shift of events had much to do with the "Total Force" policy, introduced in 1970 by the thenSecretary of Defense Melvin Laird [2]. To reduce defense costs, the concept integrated active and reserve forces. The Army Reserve assumed much of the combat support and combat service support for active force units, and the ARNG augmented combat divisions. With the continued threat of thermonuclear warfare, the reserve force continued to serve as a strategic deterrent from about 1970 through 1980. The strategic role of the reserve force worked well for the citizen who served part-time in the military. However, undeniably, reserve forces were now necessary for any large-scale military operation [34,35]. The First Gulf War (Operation Desert Storm) was the first real test of the Total Force Policy, necessitating the call-up of reservists more than 84,000 Army Reserve and 60,000 Army National Guard (ARNG) soldiers [24]. However, reservists performed active military service only for a relatively short period of time due to war's short length. In contrast, the current wars in Iraq and Afghanistan necessitated the call-up of many more reservists for periods of one to two years, often more than once.

Of immediate policy and research interest was whether reservists were prepared for deployments. Studies conducted during initial deployments hinted at problems of readiness [7,9,11,12]. Demands of changed missions meant reservists had to be better prepared for overseas missions, usually requiring more time for training and deployment, taking time away from family and from civilian work. Observed inadequacies resulted in several initiatives to improve individual and unit readiness, including the Reserve Component Training Development Action Plan aimed at improving individual soldier skills and leader effectiveness; the Leader Development Action Plan [31] to better select, educate, and assess leaders; the "Bold Shift" initiative [30] prescribing policies and procedures for combat maneuvers during peacetime, and Title XI [20] to better prepare individual and unit readiness for mobilization and deployment.

At present, the historically part-time nature of reserve military service has been replaced by the realities of frequent and lengthy deployments. Operations Iraqi Freedom (OIF) and Enduring Freedom (OEF) resulted in the activation of about 300,000 of the 1.2 million ARNG and Army Reserve soldiers to support military missions for homeland security and operations in Afghanistan and Iraq [10]. As a result, more recent research and policy interests have shifted to the unique stresses associated with reserve military service, such as going from part-time to full-time military service, being deployed frequently and for long time periods, and maintaining civilian employment and positive family relations while deployed. Unlike full-time active duty soldiers, reserve soldiers leave their fulltime civilian employment while deployed and serving full-time in military service. Reservists resume civilian employment after having been deployed and reverting to part-time military service. Castaneda et al. [3] interviewed 600 Guard and Reserve families who had experienced at least one overseas deployment since September 2001. They reported that service members were more likely to name arranging for household responsibilities as a major consideration for being prepared for deployments, whereas spouses were more likely to name social and emotional well-being with spouses of Army Guard soldiers, describing themselves as least prepared among reserve spouses. Those service members and spouses who received little notice of deployments were more likely to name household responsibilities, financial and legal concerns, and continuation of civilian employment as problems during deployment.

\subsection{Civilian employment of reservists}

Civilian employment is the primary livelihood of reservists and introduces another unique aspect of reserve military duty. After deployment, reservists have 
to re-establish relationships with their civilian employers and work, unlike active duty personnel. While there are numerous examples of this being done without problems, there are also examples where reservists have been given lesser jobs, laid-off, etc., even when contrary to federal law [3,4], causing reservists additional worries. According to federal law, employers of reservists must offer returning reservists the same or similar jobs as they had before having been deployed. Issues of re-employment and prevalence of postwar adjustment problems [13], including suicide [14,15] brought greater attention to financial hardships of reservists who were activated, namely, pay equity while deployed and subsequent re-employment after returning. Even so, there have been few studies examining the employment hardships experienced by reservists when deployed and after having returned. Schumm et al. [29] gathered survey responses of reservists in the First Gulf War concerning the increased overseas deployment requirements for reservists. About onehalf of those surveyed reported that new mission requirements pose difficulties for civilian employment $(41.6 \%)$ and family life $(51.1 \%)$. Many respondents reported less willingness to remain in reserve military service or to stay long enough to retire.

Turning to the more recent conflicts, Harvey et al. [17] reported postdeployment experiences of a large sample of UK reserve personnel. Compared to active duty personnel, reserve personnel were more likely to report being unsupported by the military and having difficulties in postdeployment. Perceived lack of support, either military or non-military, was associated with increased probable posttraumatic stress disorder (PTSD) and alcohol misuse. Riviere et al. [28] examined the responses of ARNG soldiers concerning postdeployment employment and adjustment at two time periods, 3 and 12 months after deployment. Civilian job loss was associated with depression 3 and 12 months later and PTSD 12 months later. Soldiers who reported that their deployment absence had negative effects on coworkers were also more likely to report PTSD symptoms at both time periods. Other studies have not shown greater unemployment among returning reservists but rather diminished work performance related to postdeployment mental health diagnosis. Erbes et al. [8], for example, examined responses of ARNG and Army Reserve personnel at two time periods - after returning from a 16-month OIF deployment and one year later. Soldiers with PTSD, major depressive disorder, or alcohol abuse or dependence did not differ in employment status from soldiers without a diagnosis at either time point. However, those with a diagnosis of PTSD, depression, and/or alcohol abuse reported lower levels of work role functioning. In addition, soldiers with PTSD reported greater rates of deterioration in work role functioning over time.

\section{Study objectives}

Findings from the studies above suggest returning deployed reservists are vulnerable to depression and PTSD symptoms, in particular, those having postdeployment employment difficulties $[13,28]$. To elaborate beyond these findings is difficult due to the few studies in the research literature. Lacking, too, is a more detailed examination of changed employment and financial statuses in relation to deployment and postdeployment experiences. In the present study, survey responses obtained from a large sample of deployed ARNG soldiers afforded the opportunity to perform these examinations. Of interest was changed financial status from deployment to postdeployment and the associations of both deployment and postdeployment experiences to changed financial status. The study provides estimates of ARNG soldiers who resumed predeployment jobs after returning from deployment and estimates of changed financial status from deployment to postdeployment. The study also reports associations of deployment and postdeployment experiences, such as the quality of unit relationships, social support, combat exposure, and negative feelings, on these estimates.

\section{Method}

\subsection{Data source}

The source of data was the Reintegration Unit Risk Inventory (R-URI), a survey administered to members of ARNG units during calendar year 2010. The R-URI is administered and funded by the U.S. Army Substance Abuse Program (ASAP). Commanders are encouraged to offer the inventory to unit members 6090 days after returning from deployment as a part of their unit reintegration. Unit members voluntarily completed the inventory. To protect anonymity, individual level responses are recorded with limited demographic information and no personally identifiable information, such as age, gender, race, rank, etc. Responses are then routinely concatenated by unit and reported back to unit leaders. 
Table 1

Sample description: Deployment location, deployment length, time since returned from deployment, and unit type

\begin{tabular}{|c|c|}
\hline Sample characteristic & $\%$ of sample \\
\hline $\begin{array}{l}\text { Deployment location } \\
\text { OIF (Iraq) } \\
\text { OEF (Afghanistan) } \\
\text { Operation Noble Eagle } \\
\text { Other }\end{array}$ & $\begin{array}{r}83.5 \\
15.7 \\
0.6 \\
0.2\end{array}$ \\
\hline $\begin{array}{l}\text { Deployment length } \\
\text { 0-6 months } \\
7-12 \text { months } \\
\text { 13-24 months } \\
\text { More than 1 year }\end{array}$ & $\begin{array}{r}1.8 \\
89.8 \\
7.8 \\
0.5\end{array}$ \\
\hline $\begin{array}{l}\text { Time since returned } \\
\text { Less than or equal to } 3 \text { months } \\
4 \text { to } 6 \text { months } \\
7 \text { to } 12 \text { months } \\
\text { More than } 1 \text { year }\end{array}$ & $\begin{array}{r}45.2 \\
43.1 \\
7.2 \\
4.5\end{array}$ \\
\hline $\begin{array}{l}\text { Number of deployments in last } 6 \text { y } \\
\text { One } \\
\text { Two } \\
\text { Three } \\
\text { Four or more }\end{array}$ & $\begin{array}{c}64.9 \\
29.3 \\
4.8 \\
0.9\end{array}$ \\
\hline $\begin{array}{l}\text { Unit type } \\
\text { Combat arms } \\
\text { Combat support } \\
\text { Combat service support } \\
\text { Other }\end{array}$ & $\begin{array}{r}37.6 \\
48.5 \\
10.4 \\
3.5\end{array}$ \\
\hline Column $\mathrm{N}$ ranged & 4460 to 4640 \\
\hline
\end{tabular}

\subsection{Sample description}

A total of 50 units comprised the sample, with 4,567 responding soldiers. The survey data provided reasonably good estimates of the units, as most of the unit members completed the survey. The mean response rate of units was $90.2 \%$, with a range of 55-100\%. Less certain was how well the survey data represented deployed ARNG personnel in 2009. The inventory did not ask about soldier background and other personal information, which could then be compared with appropriate ARNG population information to determine representativeness. Instead, unit type of units (combat arms, combat service, and combat service support) comprising the sample was available. The distribution of unit type for those units in the sample was compared to that of deployed units during the same time period. Although there was some variation, units generally represented the distribution of unit types deployed in 2009-2010. Table 1 displays descriptive statistics for the analytic sample.

Most of the soldiers had returned from OIF (83.5\%) and some (15.7\%) from OEF. Nearly the entire sample of soldiers $(90 \%)$ had been deployed for a period of seven months or longer. Only 10\% had returned seven months ago or longer, and the remaining soldiers were split equally in having returned three months (45\%) or four to six months ago (43\%). Two-thirds of the sample had been deployed once (65\%), about one-third (29\%) had been deployed twice, and the remaining (about $6 \%$ ) had been deployed more than two times.

\subsection{Questionnaire content}

The questionnaire inventory consists of 80 survey items. The survey's primary purpose is to screen for problem behaviors and attitudes of soldiers, which may have occurred during deployment or postdeployment. Content of items includes: alcohol use, illicit substance use, suicide thoughts, physically harming others, combat experiences (e.g., saw someone wounded or killed, engaged in combat, or killed someone), stressors after deployment (financial difficulties, loss of significant other, etc.), and perceived social support (e.g., work well with others in the unit and trust in unit leaders to share personal problem). In addition, information about the deployment is collected, such as location and length of deployments, and length of time since returning from deployment.

Responses to the inventory questions were used to group soldiers based on having resumed their predeployment employment and postdeployment financial difficulties (called comparison groups). To determine possible associated conditions with the employment and financial status, the groups of soldiers were then compared on various deployment and postdeployment experiences (called study variables). Specific details on deriving comparison groups and study variables are described below.

\subsection{Comparison groups}

Soldiers were grouped into four categories by crossclassification of responses to having resumed their predeployment jobs and having experienced postdeployment financial hardships. The four resulting soldier groups were:

(1) Those who returned and did not resume their predeployment jobs and experienced financial hardships (6.4\% of the study sample);

(2) Those who returned and resumed their predeployment jobs and did not experience financial hardships (29.7\% of the study sample);

(3) Those who returned and resumed their predeployment jobs and experienced financial hardships (6.2\% of the study sample); and 
Table 2

Cross-tabulation of deployment financial difficulties by postdeployment financial difficulties, overall and by not having resumed or having resumed predeployment

\begin{tabular}{|c|c|c|c|c|}
\hline $\begin{array}{l}\text { Postemployment } \\
\text { financial hardship }\end{array}$ & $\begin{array}{c}\text { No deployment } \\
\text { financial difficulties }\end{array}$ & $\begin{array}{c}\text { Deployment financial } \\
\text { difficulties }\end{array}$ & $\begin{array}{c}\text { Row total } \\
\%\end{array}$ & $\mathrm{X}^{2}$ test \\
\hline No & $86.3 \%$ & $1.9 \%$ & $88.2 \%$ & $122.00^{* * *}$ \\
\hline Yes & $6.6 \%$ & $5.2 \%$ & $11.8 \%$ & \\
\hline Column total \% & $92.9 \%$ & $7.1 \%$ & & \\
\hline \multicolumn{5}{|c|}{ Percentages are based on total sample size; $N=4,474$. } \\
\hline \multicolumn{5}{|c|}{ For soldiers reporting NOT resuming predeployment jobs } \\
\hline $\begin{array}{l}\text { Postemployment } \\
\text { financial hardship }\end{array}$ & $\begin{array}{c}\text { No deployment } \\
\text { financial difficulties }\end{array}$ & $\begin{array}{c}\text { Deployment financial } \\
\text { difficulties }\end{array}$ & $\begin{array}{c}\text { Row total } \\
\% \\
\end{array}$ & $\mathrm{X}^{2}$ test \\
\hline No & $80.4 \%$ & $1.7 \%$ & $82.1 \%$ & $351.00^{* * *}$ \\
\hline Yes & $10.4 \%$ & $7.5 \%$ & $17.9 \%$ & \\
\hline Column total \% & $90.8 \%$ & $9.2 \%$ & & \\
\hline \multicolumn{5}{|c|}{ Percentages are based on total sample size; $N=2,231$. } \\
\hline \multicolumn{5}{|c|}{ For soldiers reporting resuming predeployment jobs } \\
\hline $\begin{array}{l}\text { Postemployment } \\
\text { financial hardship }\end{array}$ & $\begin{array}{c}\text { No deployment } \\
\text { financial difficulties }\end{array}$ & $\begin{array}{c}\text { Deployment financial } \\
\text { difficulties }\end{array}$ & $\begin{array}{c}\text { Row total } \\
\%\end{array}$ & $\mathrm{X}^{2}$ test \\
\hline No & $88.4 \%$ & $1.9 \%$ & $90.3 \%$ & $555.90^{* * *}$ \\
\hline Yes & $5.6 \%$ & $4.1 \%$ & $9.7 \%$ & \\
\hline Column total \% & $94.0 \%$ & $6.0 \%$ & & \\
\hline
\end{tabular}

(4) Those who returned and did not resume their predeployment jobs and did not experience financial hardships ( $57.7 \%$ of the study sample).

\subsection{Study variables}

Soldiers responded to questions that pertained to deployment. Questions asked about personal wellbeing (e.g., feelings of anger and frustration, suicide thoughts), interpersonal distress (e.g., loss of significant relationship), available social support (e.g., trust in the unit chain-of-command, work well with unit members, people who provide support), and having financial difficulties. Soldiers were also asked about combat experiences while deployed - whether they had experienced trauma, engaged in combat, wounded or killed others, had seen others wounded or killed, and lost a friend in combat. Postdeployment questions were similar to deployment questions asking about personal well-being, interpersonal distress, available social support, and financial difficulties. Soldiers were also asked about general symptoms of posttraumatic stress, namely, upsetting memories and trouble sleeping.

\subsection{Analysis approach}

There were two general approaches to the analysis. First, responses of the four groups of soldiers were compared using one-way analysis of variance (ANOVA), with post hoc pairwise comparisons. Second, to determine the relative contribution of deployment and postdeployment conditions to changed financial status, logistic regression analysis was conducted. Postemployment financial difficulties were predicted by responses to the deployment questions (i.e., personal well-being, interpersonal distress, available social support, and financial difficulties) and responses to the postdeployment questions (e.g., personal wellbeing, interpersonal distress, available social support, and general symptoms of posttraumatic stress), including having resumed the predeployment job. Thus, results showed the association of predictor variables with changed financial status, from deployment to postemployment [6, pp. 570-573]. Also, of interest was the amount of variance that sets of variables accounted for in the total explained variance $\left(\mathrm{R}^{2}\right.$ Change), for example, deployment financial difficulties, deployment support and combat exposure, etc. Two logistic regression equations were performed. The first regression included all the study variables. The second regression included only those study variables which were statistically significant in the first regression, along with interactions between having resumed the predeployment job and significant predictor variables. These interactions permitted the examining the extent to which having resumed the predeployment job attenuated effects of the predictor variable on changed financial status. 
Table 3

Comparison of mean values on study variables by reemployment and financial difficulties

\begin{tabular}{|c|c|c|c|c|c|}
\hline \multirow[b]{2}{*}{$\begin{array}{l}\text { Survey item arranged by } \\
\text { deployment, combat, and } \\
\text { postdeployment } \\
\text { experiences }\end{array}$} & \multicolumn{4}{|c|}{ Mean Values (proportions or scale response) } & \multirow[b]{2}{*}{ F-value } \\
\hline & $\begin{array}{c}\text { No resumed job, } \\
\text { Troubled finances } \\
\quad N=224 \\
(6.4 \%)\end{array}$ & $\begin{array}{c}\text { No resumed job, } \\
\text { No troubled finances } \\
N=1038 \\
(29.7 \%)\end{array}$ & $\begin{array}{c}\text { Job resumed, } \\
\text { Troubled finances } \\
N=218 \\
(6.2 \%)\end{array}$ & $\begin{array}{c}\text { Job resumed, } \\
\text { No troubled finances } \\
N=2019 \\
(57.7 \%)\end{array}$ & \\
\hline \multicolumn{6}{|l|}{ During deployment } \\
\hline 21. Financial trouble & 0.42 & 0.02 & 0.42 & 0.02 & $420.54^{* * *}$ \\
\hline 14. Work well with unit members & 0.83 & 0.89 & 0.88 & 0.91 & $4.77^{* *}$ \\
\hline 15. Trust chain of command & 0.51 & 0.62 & 0.56 & 0.67 & $9.70^{* * *}$ \\
\hline 19. Available support & 2.16 & 2.42 & 2.24 & 2.49 & $18.16^{* * *}$ \\
\hline 17. Angry and frustrated & 0.69 & 0.46 & 0.67 & 0.41 & $35.21 * * *$ \\
\hline 18. Lonely & 0.41 & 0.19 & 0.32 & 0.17 & $32.61^{* * *}$ \\
\hline 20. Loss of relationship & 0.44 & 0.29 & 0.36 & 0.19 & $36.35^{* * *}$ \\
\hline 24. Suicide thoughts & 0.15 & 0.04 & 0.09 & 0.03 & $31.01^{* * *}$ \\
\hline \multicolumn{6}{|l|}{ Combat exposure } \\
\hline 29. Experience trauma & 0.37 & 0.20 & 0.31 & 0.17 & $20.90^{* * *}$ \\
\hline 30. Engaged in combat & 0.26 & 0.22 & 0.24 & 0.17 & $5.89^{* * *}$ \\
\hline 31. Wound/kill others & 0.08 & 0.06 & 0.06 & 0.03 & $5.81^{* * *}$ \\
\hline 32. See others wounded/killed & 0.49 & 0.51 & 0.52 & 0.46 & $2.97^{*}$ \\
\hline 33. Lose friend in combat & 0.17 & 0.13 & 0.13 & 0.17 & $3.01^{*}$ \\
\hline \multicolumn{6}{|l|}{ Postdeployment } \\
\hline 47. Work well with unit members & 0.81 & 0.90 & 0.88 & 0.93 & $13.84^{* * *}$ \\
\hline 48. Trust chain of command & 0.50 & 0.65 & 0.58 & 0.68 & $11.29 * * *$ \\
\hline 52. Available support & 2.07 & 2.43 & 2.26 & 2.50 & $23.72 * * *$ \\
\hline 50. Angry and Frustrated & 0.64 & 0.33 & 0.66 & 0.30 & $68.78^{* * *}$ \\
\hline 51. Lonely & 0.41 & 0.16 & 0.30 & 0.12 & $55.10^{* * *}$ \\
\hline 53. Loss of relationship & 0.40 & 0.22 & 0.33 & 0.14 & $44.86^{* * *}$ \\
\hline 6. Alcohol use & 1.82 & 1.90 & 1.88 & 1.80 & 1.63 \\
\hline 69. Upsetting memories & 0.42 & 0.21 & 0.39 & 0.18 & $34.86^{* * *}$ \\
\hline 70. Trouble sleeping & 0.70 & 0.46 & 0.60 & 0.36 & $48.33^{* * *}$ \\
\hline 57. Suicide thoughts & 0.12 & 0.03 & 0.13 & 0.03 & $32.52 * * *$ \\
\hline
\end{tabular}

Notes. Multivariate F test, Wilk's Lambda F $(3,3998)=25.46, p<0.001$ to test differences between the comparison groups across all study variables. Item 6 was coded as "Never" (coded as 0), "Monthly" (1), "2 to 3 times a month" (2), 2 to 3 times a week (3), and " 4 or more times a week" (4); and SE was generally .07 for each mean value. Items 19 and 52, response options were: "Always" (coded as 3), "Sometimes" (2) "Hardly Ever" (1), and "Never" (0); and SE was generally .07 for each mean value. Response options for remaining items were: "Yes" (1) and "No" $(0)$ and SEs was generally .03 for each proportion. Comparison of two means in any row would have to exceed about twice the SE in order for the means to be considered reliably different. ${ }^{*} p<0.05 ;{ }^{* *} p<0.01 ;{ }^{* * *} p<0.001$.

For example, negative feelings associated with financial hardships may be less for those who resumed predeployment employment than those who did not resume the predeployment job.

\section{Results}

Overall, few soldiers reported financial difficulties during deployment (7.1\% of the sample) and after having returned $(11.8 \%)$. Of the $11.8 \%(527 / 4,474)$ of the sample that experienced postdeployment financial difficulties, nearly one-half had reported such difficulties during deployment (5.2\% of the total sample). Table 2 displays a cross-tabulation of financial difficulties - deployment by postdeployment - in addition to having resumed the predeployment job or not.

Not having resumed the predeployment job was associated with more postdeployment financial diffi- culties. There was a greater percentage of soldiers $(17.9 \%)$ who reported postdeployment financial difficulties who had not resumed the predeployment job than those soldiers who had resumed the predeployment job yet had postdeployment difficulties (9.8\%). Additionally, those soldiers who reported deployment financial difficulties and had not resumed the predeployment job showed a greater percentage of increased postdeployment financial difficulties $(1.7 \%$ to $7.5 \%)$ than those soldiers who reported deployment financial difficulties and had resumed the predeployment job $(1.9 \%$ to $4.2 \%)$.

\subsection{Comparing the solider groups on study variables}

The first approach of the analysis was to perform comparisons on the study variables across the four soldier groups. Table 3 displays results. 
Table 4

Prediction of postdeployment financial difficulties by study variables, with emphasis on having resumed predeployment job or not

\begin{tabular}{|c|c|c|c|c|}
\hline \multirow{2}{*}{$\begin{array}{l}\text { Survey item arranged by } \\
\text { deployment, combat, and } \\
\text { postdeployment experiences }\end{array}$} & \multicolumn{2}{|c|}{ Full model } & \multicolumn{2}{|c|}{ Parsimonious model } \\
\hline & B (SE) & Odds ratio & $\mathrm{B}(\mathrm{SE})$ & Odds ratio \\
\hline 21. Financial trouble & $-12(36)$ & 0.89 Chg $^{2}=0.006$ & $15(33)$ & 1.16 Chg R $^{2}=0.008$ \\
\hline $\begin{array}{l}\text { During deployment } \\
\text { 14. Work well with nit members } \\
\text { 15. Trust chain of command } \\
\text { 19. Available support } \\
\text { 20. Loss of relationship } \\
\text { 17. Angry and Frustrated } \\
\text { 18. Lonely } \\
\text { 24. Suicide thoughts }\end{array}$ & $\begin{aligned} & 02(35) \\
&-60(34)+ \\
&-49(17)^{* *} \\
& 38(28) \\
&-32(31) \\
& 09(31) \\
& 12(46)\end{aligned}$ & $\begin{array}{rl}1.02 & 0.55 \\
0.61 \mathrm{Chg} \mathrm{R}^{2} & =0.056 \\
1.43 & \\
0.73 & \\
1.09 & \\
1.12 \mathrm{Chg} \mathrm{R}^{2}=0.045\end{array}$ & $\begin{array}{l}-55(34) \\
-19(21)\end{array}$ & $\begin{array}{c}0.58 \\
0.82 \text { Chg R }^{2}=0.052\end{array}$ \\
\hline $\begin{array}{l}\text { War exposure } \\
\text { 29. Experience trauma } \\
\text { 30. Engaged in combat } \\
\text { 31. Wound/kill others } \\
\text { 32. See others wounded/killed } \\
\text { 33. Lose friend in combat }\end{array}$ & $\begin{array}{l}06(29) \\
27(28) \\
06(40) \\
73(26)^{* *} \\
-16(30)\end{array}$ & $\begin{array}{r}1.06 \\
1.31 \\
1.06 \\
2.01 \\
0.86 \text { Chg R }^{2}=0.036\end{array}$ & $1.25(36)^{* * *}$ & $3.49 \mathrm{Chg} \mathrm{R}^{2}=0.024$ \\
\hline $\begin{array}{l}\text { Postdeployment } \\
\text { 47. Work well with unit members } \\
\text { 48. Trust chain of command } \\
\text { 52. Available support } \\
\text { 53. Loss of relationship } \\
\text { 50. Angry and Frustrated } \\
\text { 51. Lonely }\end{array}$ & $\begin{aligned}-40 & (37) \\
10 & (33) \\
32 & (17)+ \\
36 & (30) \\
51 & (30)+ \\
-11 & (32)\end{aligned}$ & $\begin{array}{rl}0.67 & 1.11 \\
1.38 \text { Chg R }^{2} & =0.005 \\
1.44 & \\
1.67 & \\
0.89 \text { Chg R }^{2}=0.013\end{array}$ & $\begin{array}{l}21(21) \\
34(35)\end{array}$ & $\begin{array}{l}\text { 1.23 Chg R }{ }^{2}=0.001 \\
1.41 \mathrm{Chg} \mathrm{R}^{2}=0.028\end{array}$ \\
\hline $\begin{array}{l}\text { Q6. Alcohol use } \\
\text { 69. Upsetting memories } \\
\text { 70. Trouble sleeping } \\
\text { 57. Suicide thoughts } \\
\text { 5. Resumed job }\end{array}$ & $\begin{aligned} & 70(10)^{* * *} \\
19 & (28) \\
48 & (28)+ \\
78 & (47)+ \\
-37 & (22)+\end{aligned}$ & $\begin{aligned} 2.02 & \\
1.21 & \\
1.62 & \\
2.18 \mathrm{Chg} \mathrm{R}^{2} & =0.075 \\
0.69 \mathrm{Chg} \mathrm{R}^{2} & =0.004\end{aligned}$ & $\begin{array}{l}70(14)^{* * *} \\
78(38)^{*} \\
1.75(43)^{* * *} \\
75(1.04)\end{array}$ & $\begin{aligned} 2.02 & \\
2.17 & \\
5.73 \mathrm{Chg} \mathrm{R}^{2} & =0.106 \\
2.12 \mathrm{Chg} \mathrm{R}^{2} & =0.006\end{aligned}$ \\
\hline $\begin{array}{l}\text { Interactions - Resumed job X: } \\
\text { 15. Deployment unit trust } \\
\text { 19. Deployment available support } \\
\text { 32. See others killed in combat } \\
\text { 50. Postdeployment anger } \\
\text { 52. Postdeployment support } \\
\text { 53. Postdeployment loss } \\
\text { 6. Postdeployment alcohol } \\
\text { 70. Postdeployment sleep troubles } \\
\text { 57. Postdeployment suicide thoughts }\end{array}$ & $\begin{array}{c}\text { Not } \\
\text { applicable }\end{array}$ & & $\begin{array}{c}08(48) \\
-65(30)^{*} \\
-72(47) \\
47(50) \\
21(30) \\
13(48) \\
08(20) \\
-32(51) \\
-1.36(70)^{*}\end{array}$ & $\begin{array}{r}1.09 \\
0.52 \\
0.48 \\
1.60 \\
1.23 \\
1.14 \\
1.08 \\
0.73 \\
0.26 \text { Chg R }^{2}=0.014\end{array}$ \\
\hline $\begin{array}{l}\text { Constant } \\
X^{2}(d f=24), N=2,951 \\
X^{2}(d f=18), N=3,289 \\
\text { Pseudo } R^{2}\end{array}$ & $\begin{array}{c}-5.10(57) \\
189.08^{* * *} \\
0.240\end{array}$ & & $\begin{array}{c}-6.24(78) \\
199.33^{* * *} \\
0.239\end{array}$ & \\
\hline
\end{tabular}

Note. Decimals have been omitted except for integer coefficients. ${ }^{*} p<0.05 ;{ }^{* *} p<0.01 ;{ }^{* * *} p<0.001$.

The majority of soldiers did not experience postdeployment financial difficulties $(87.5 \%$ of the study sample). The remaining soldiers reported financial difficulties with about one half who resumed their jobs and one half who did not. Noteworthy, too, is that one-third $(29.7 \%)$ of the sample did not resume their predeployment jobs but had reported no postdeployment financial hardships. The four soldier groups were compared across several study variables, which necessitated a multivariate $\mathrm{F}$ test. The groups varied significantly across all study variables (Wilk's Lambda
$\mathrm{F}(3,3998)=25.46, p<0.001)$. To determine on which specific study variables the groups differed, several one-way analyses of variance (ANOVAs) were conducted. Study variables were organized by deployment, combat exposure, and postdeployment.

The groups differed on all study variables, except for alcohol consumption during postdeployment. Soldier groups which fared worse across study variables were those soldiers who experienced financial difficulties after return from deployment, in particular on: (1) experiences while deployed, such as lacking so- 
cial support, having lost significant others, being angry and frustrated, having suicide thoughts, having experienced combat trauma; and (2) experiences after having returned from deployment, such as having lost significant others, being angry and frustrated, and having upsetting memories and trouble sleeping. Differences between postdeployment financially troubled groups were few - even when considering whether soldiers had resumed predeployment jobs. By contrast, the two soldier groups which fared better on the study variables were those who reported no postdeployment financial difficulties.

\subsection{Predicting changed financial status}

Multivariate logistic regression analyses were then done to examine the relative contribution of study variables to changed financial difficulties, from deployment to postdeployment. Two logistic regression analyses were conducted. One analysis included all study variables, called the full model (see Table 3 ).

Predictor variables in the full model explained $24.0 \%$ of the variation in changed financial difficulties. Variable groups that contributed most to the explained variance (see $\mathrm{R}^{2}$ Change) were: deployment perceived support $(5.6 \%)$ and deployment negative feelings and personal loss $(4.5 \%)$; combat exposure $(3.6 \%)$; and postdeployment well-being $(7.5 \%)$. In the full model, deployment perceptions of trust in the unit chain-ofcommand and available support were associated with decreased financial difficulties. In contrast, increased financial difficulties were associated with having seen others wounded or killed in combat. Several postdeployment experiences, such as feelings of anger and frustration and available support were also associated with increased financial difficulties. Regarding available support, it may be, due to financial hardships, soldiers have now called on and depend more on friends, neighbors, and relatives for assistance. Postdeployment alcohol use, trouble sleeping and suicide thoughts were associated with increased financial difficulties. Having resumed the predeployment job was associated with decreased financial difficulties.

The second regression included only those study variables which were statistically significant in the first regression, called the parsimonious model. The regression analysis also included interactions between having resumed the predeployment job and significant predictor variables. These interactions permitted examining the extent to which having resumed the predeployment job attenuated effects of the predictor vari- able on changed financial difficulties. Results are presented in the last two columns of Table 3. Predictor variables in the parsimonious model explained $23.9 \%$ of the variation in changed financial difficulties. Variable groups that accounted for most of the explained variance (see $\mathrm{R}^{2}$ Change) were unit and other support provided during deployment $(5.2 \%)$, postdeployment negative feelings and personal loss $(2.8 \%)$, and postdeployment negative well-being, such as alcohol use, sleep troubles, and suicide thoughts $(10.6 \%)$. Combat exposure contributed $2.4 \%$ to the total explained variance. Several variables showed strong associations with increased financial difficulties. Soldiers who reported having seen others wounded or killed in combat were 3.49 times more likely to report increased financial difficulties than those who had not seen such trauma. Soldiers who reported alcohol use and sleeping problems were twice as likely to report increased financial difficulties as soldiers without such conditions. Finally, those soldiers who had suicide thoughts were nearly six times more likely to report increased financial difficulties than soldiers without such thoughts. Having resumed the predeployment job contributed a small amount of variance to the total explained variance $(0.6 \%)$. When examining variations in the relationship between changed financial difficulties and the predictor variables, having resumed the predeployment job appeared to lessen the negative effects of postdeployment suicide thoughts on increased financial difficulties (evident from negative coefficient of interaction variable). Having resumed the predeployment job appeared to augment deployment social support to lessen changes in financial difficulties (evident from negative coefficient of interaction variable).

\section{Conclusions}

The present study had two general purposes - (1) to describe changes in financial difficulties of ARNG soldiers from deployment to postdeployment, including having resumed predeployment jobs; and (2) to examine associations of deployment and postdeployment experiences (e.g., unit and other support, combat exposure, and negative feelings) with postdeployment financial difficulties and employment. Results here suggest that changes in financial difficulties from deployment to postdeployment likely relate to a collection of several factors - circumstances unique to reservists at predeployment and during deployment, such as civilian employment, available unit and other support and 
negative feelings, and again, such circumstances after having returned from deployment. The dynamic interplay among this collection of factors likely relates to postdeployment personal adjustment, successful resumption of civilian employment, and effective management of household finances. To summarize results, relatively few soldiers experienced financial difficulties during deployment (7.1\%) and afterwards (11.8\%). Some soldiers' financial difficulties emerged after returning from deployment. Of the $11.8 \%$, about onehalf reported financial difficulties only after deployment. The remaining one-half had reported difficulties during and after deployment, and for these soldiers not having resumed predeployment jobs was more strongly associated with increased financial difficulties. Results from the multivariate logistic regression analyses suggest precipitating conditions of financial difficulties include financial troubles at the deployment and traumatic combat events, such as having seen people killed or wounded. Unit support and support provided by others during deployment potentially mitigated financial difficulties from deployment to postdeployment. Postdeployment consequences associated with increased financial difficulties included alcohol use, sleeping difficulties, and suicide thoughts. Having resumed predeployment jobs appeared to lessen the negative effects of postdeployment suicide thoughts on increased financial difficulties. Having resumed predeployment jobs also appeared to augment deployment social support to lessen changes in financial difficulties. Results point to several areas having implications for policy and practice, namely how to prepare soldiers and families to adjust for changes in financial and employment status; how to develop unit and other support for soldiers and families who experience financial hardships; and finally, how to take into account deployment experiences that negatively impact postdeployment financial and employment status. Each is discussed in greater detail below.

\subsection{Preparing for financial consequences of deployment}

Results imply helping reservists plan for deployments, in particular, preparing for adverse effects of deployment on household finances. Greater predictability of deployments would allow for reservists to plan their extended absences with families and employers, potentially eliminating many adverse consequences for reservists, their families, and their employers. Employers are equally wanting of predictability [26]. To some extent the Army Force Generation (ARFORGEN) policy ${ }^{2}$ accomplishes this by specifying time periods during which reservists can expect their unit to be deployed. A template of activities for reservists should be developed that instructs both reservists and their employers of appropriate procedures for notification, activities while deployed, and resuming employment. Methods should be developed to maintain contact with employers while reservists are deployed up to a year or more, informing employers of the deployment, expected return, and planned reception of reservists. These activities should lessen difficulties in transitioning from civilian employment, arranging for employment benefits during and after deployment, and in returning to the previous job position. Reservists should continue to be informed of their employment rights, areas of potential employer conflicts, and ways to effectively resolve them. The Employer Support of the Guard/Reserve (ESGR) should continue to monitor problems reservists have with employers. Gathering systematic data suggests areas for future actions, whether preventive activities or changes in federal policies. Finally, more should be done to remedy pay equity issues of reservists employed by state and municipal governments and by private business, offering tax benefits in return. To address deployed reservists' financial worries, the federal government directed its agencies to provide pay differential between reserve pay and the federal civilian salary [25].

Results here also imply financial and employment counseling might occur irrespective of deployment. A substantial percentage of soldiers who reported financial difficulties both during and after deployment, and for these soldiers not having resumed predeployment jobs was more strongly associated with increased financial difficulties than those soldiers who resumed predeployment jobs. Reservists who experience financial difficulties may have such difficulties before deployment, perhaps, due to civilian under-employment or unemployment. Reservists also likely serve for broader meaning and purpose, rather than for pay [20, 36], and when serving full-time on active duty, do not have comparable financial resources as they did when serving part-time on traditional reserve duty. A possible direction is allowing reservists to access the Army Transition Assistance Program (TAP) ser-

${ }^{2}$ The Army Force Generation (ARFORGEN) policy specifies phases for units and their members during a 5-year cycle, divided into roughly equal time periods, during which units reset, train and achieve mission readiness, and are available for deployment. 
vices or similar services available to reservists at any time during the ARFORGEN cycle. At present, soldiers are to schedule a pre-separation counseling at their installation's TAP/Army Career Alumni Program (ACAP). The soldier drafts an Individual Transition Plan, specifying career and job goals and, in turn, TAP staff determines which services are best suited to assist the soldier in reaching his or her goals. Services include U.S. Department of Labor employment workshops, resume-writing assistance, job application preparations, and participation in the Employer Partnership for the Armed Forces, a group of companies and agencies committed to hiring veterans. These services might be extended to reservists during predeployment cycle of ARFORGEN to develop reservists' employment opportunities and earnings.

\subsection{Unit and social support provided to soldiers}

Results point to the benefits of unit and social support in lessening financial difficulties. Both unit support and other social support were associated with decreased financial difficulties. Having resumed predeployment jobs appeared to mitigate the negative effects of deployment and postdeployment conditions on postemployment financial difficulties. Taking predeployment jobs likely offers familiar and available supports - coworkers, supervisors, and organizational resources. Well-documented in the health literature are the positive benefits of social support on mental and physical well-being [27], in particular, when experiencing stressful life circumstances [5]. Social support augments the individual's ability to cope through the provision of resources, such as emotional support; tangible material assistance, information, advice and guidance; and companionship [23]. Most recently, Griffith and West [13] provided evidence for the buffering effect of social support (both at the individual and group levels) on postdeployment risk behaviors of ARNG soldiers. Part of the ARFORGEN cycle should be dedicated effort to develop and maintain supports provided by the unit and other families. While much attention has been given to postdeployment [18,32], more planned effort should be done to better network families to provide necessary and accessible support during all phases of the ARFORGEN cycle, including predeployment, deployment, and postdeployment. Families might form subgroups responsible for specific support, such as household chores, chauffeuring children to activities, financial assistance and management, emotional support, etc. [3]. Provision of such support is more challenging for reservists than active duty soldiers. Unlike their active duty counterparts, after returning from deployment, reservists typically revert to part-time military status, and aside from monthly drills, have limited contact with unit members. More effort should be devoted to networking reserve families who live nearby, even those not necessarily in the same unit or reserve component. Part of this planned effort should be informing family members of potential stressors, effective coping, and when and from whom to seek formal health care. Instruction should also be given instruction on how to recognize service members' symptoms and explicit procedures for unit referral and subsequent treatment [14].

\subsection{Role of deployment experiences on postdeployment employment and adjustment}

Some have argued that combat trauma, specifically, having killed someone or witnessed killing, have unique consequences, such as associated with later increased likelihood of suicide behavior $[21,22]$. In the present study, having seen someone killed or wounded was associated with increased financial difficulties. This likely relates to other findings of postdeployment adjustment. For example, soldiers who reported increased financial difficulties also reported feelings of anger and frustration, alcohol use, sleeping problems, and suicide thoughts. Cross-sectional data makes it difficult to determine the direction of such relationships. For example, postdeployment adjustment problems might affect work status and/or ability to manage household finances, or financial difficulties might lead to increased personal distress and postdeployment adjustment problems, or the three variable domains adjustment problems, employment issues and financial difficulties - might work in combination. Nevertheless, findings suggest negative effects of having been deployed, in particular, in combat zones - having seen killing and wounding of others. Postdeployment adjustment was marked by suicide thoughts, difficulty in sleeping, and alcohol use. Regardless of the directionality of findings, such adjustment problems associated with financial difficulties argues for screening for those at-risk, and subsequently, referral to treatment, and case management. Even if soldiers are screened and identified, there are significant challenges. Soldiers are geographically dispersed which may make receiving routine treatment difficult. There needs to be mechanisms to ensure soldiers follow prescribed intervention and to monitor treatment compliance. Also, obligations 
of civilian work and family compete with the soldier's time. Finally, treatment may be limited due to the soldier's private health care insurance. Similar issues of surveillance, referral, and treatment are currently faced by suicide prevention efforts in the ARNG [14].

\subsection{Study limitations}

Data used in the study have clear strengths as well as limitations. The survey data, collected routinely from soldiers having returned 60-90 days after overseas deployments, provide substantial numbers of cases for analyses. Moreover, survey items covered a broad range of content, which were administered consistently as the same item set. Nonetheless, limitations of the available data were evident. Survey item content was not explicitly designed for the purposes of the present study, and as such, did not always have all the desired data elements. The survey's anonymity-strategy meant that some relevant soldier background characteristics, such as age, gender, and race/ethnicity, and age, were not available for analysis, and it is possible study results might be different if such characteristics had been included in the analysis. Additionally, completing the survey was voluntary and not every soldier completed questionnaires, resulting in self-selected respondents. Noteworthy, however, is the distribution of unit types was similar to those unit types which were actually deployed in 2010. Other study limitations related to the data coming from one measure (questionnaire). Deployment experiences and behaviors, in addition to currently expressed stressors, may have been constructed by the soldier de facto to explain his/her current problem behaviors. Also, relationships among variables may, in part, be explained by common methods variance. To establish more definitive and causal relationships among variables, longitudinal studies of reservists should be considered, tracking individual soldiers in order to gather information on experiences at predeployment, deployment, and postdeployment. With these limitations in mind, results should be interpreted cautiously, and future studies should consider these in their designs.

\section{References}

[1] Allen, G.W. (1992). Dental health in the Army Reserves and National Guard - A mobilization problem? Executive Research Project RS3a. Fort McNair, WA: Industrial College of the Armed Forces, National Defense University.
[2] Carafano, J.J. (2005). Total Force and the Abrams doctrine: Unfulfilled promise, uncertain future. Philadelphia, PA: Foreign Policy Research Institute. Available from http:// www.fpri.org/enotes/20050203.military.carofano. totalforcepolicyabramsdoctrine.html (accessed 5 August 2010).

[3] Castaneda, L.W., Harrell, M.C., Varda, D.M., Hall, K.C., Beckett, M.K., \& Stern, S. (2009). Deployment experiences of Guard and Reserve families: Implications for support and retention. Santa Monica, CA: National Defense Research Institute, RAND.

[4] CBS News (2009). Reservists' rocky return to job market. 60 Minutes Report. Available from CBS News web site: http://www.cbsnews.com/stories/2008/10/30/60minutes/ main4558315.shtml (accessed 25April 2009).

[5] Cohen, S., \& Wills, T.A. (1985). Stress, social support, and the buffering hypothesis. Psychological Bulletin, 98, 310-357.

[6] Cohen, J., Cohen, P., West, S. G., \& Aiken, L. S. (2003). Applied multiple regression/correlation analysis for the behavioral sciences (3rd ed.). Mahwah, NJ: Erlbaum.

[7] Drew, N. S. (1994), NSC-68: Forging the strategy of containment. Report NSC-20/4, Sec. 21 (a), 31. Washington, DC: National Defense University Press. Available at http://handle. dtic.mil/100.2/ADA432148 (accessed November 4, 2009).

[8] Erbes, C.R., Kaler, M.E., Schult, T., Polusny, M.A., \& Arbisi, P.A. (2011). Mental health diagnosis and occupational functioning in National Guard/Reserve veterans returning from Iraq. Journal of Rehabilitation Research and Development, 48 (10), 1159-1170.

[9] General Accounting Office (1992). Operation Desert Storm: Army Guard combat brigade war lessons reflect longstanding problems. Testimony, GAO/T-NSIAD-92-36. Washington, DC: General Accounting Office.

[10] General Accounting Office (August, 2003). DoD actions needed to improve the efficiency of mobilizations for reserve force. Report provided to the Subcommittee on Personnel, Committee on Armed Services, U.S. Senate, report no. GAO03-921, August 2003.

[11] Griffith. J. (1995). The Army Reserve soldier in Operation Desert Storm: Perceptions of being prepared for mobilization, deployment and combat readiness. Armed Forces and Society, 21 (2) $195-215$.

[12] Griffith, J. (2005). The Army National Guard soldier in post9/11 operations: Perceptions of being prepared for mobilization, deployment, and combat. Journal of Political and Military Sociology, 33 (2), 161-77.

[13] Griffith, J. (2010). Citizens coping as soldiers: A review of postdeployment stress symptoms among deployed reservists. Military Psychology, 22, 176-206.

[14] Griffith, J. (2012a). Suicide in the Army National Guard: An empirical inquiry. Suicide and Life-Threatening Journal, 2012, 42 (1), 104-119.

[15] Griffith, J. (2012b). Army suicides - "Knowns" and an interpretative framework for future directions. Military Psychology, 24 (5), 488-512.

[16] Griffith, J., \& West, C. (2010). The Army National Guard in OIF/OEF: Relationships among combat exposure, postdeployment stressors, social support, and risk behaviors. Applied and Preventive Psychology, 2010, 14 (1/June), 86-94.

[17] Harvey, S.B., Hatch, S. L., Jones, M., Hull, L., Jones, N., Greenberg, N., Dandeker, C., Fear, N., \& Simon, W. (2011). Coming home: Social functioning and the mental health of UK reservists on return from deployment to Iraq or Afghanistan. Annals of Epidemiology, 21 (9), 666-672.

[18] Hinojosa, R., \& Hinojosa, M.S. (2011). Using military friend- 
ships to optimize postdeployment reintegration for male Operation Iraqi Freedom/Operation Enduring Freedom veterans. Journal of Rehabilitation Research and Development, 48 (10), 1145-1157.

[19] Knutsen, T.L. (1999). The rise and fall of world orders: The rise and demise of hegemonic powers in international politics. Manchester, UK: Manchester University Press.

[20] Lakhani, H., \& Fugita, S. S. (1993). Reserve/Guard retention: Moonlighting or patriotism? Military Psychology, 5 (2), 113125 .

[21] Litz, B.T., Stein, N., Delaney, E. et al. (2009). Moral injury and moral repair in wear veterans: A preliminary model and intervention strategy. Clinical Psychology Review, 29, 695706.

[22] Maguen, S.M., Metzler, T.J., Bosch, J., Marmar, C.R., Knight, S.J., \& Neylan, T.C. (2012). Killing in combat may be independently associated with suicidal ideation. Depression and Anxiety, Published online March 17, 2012.

[23] Mitchell, R.E., \& Trickett, E.J. (1980). Task force report: Social networks as mediators of social support. An analysis of the effects and determinants of social networks. Community Mental Health Journal, 16 (1), 27-44.

[24] Nelson, H.W., Army, H., Jacobs, B., \& Bluhm, R.K. (2001) (Eds.). The Army. Westport, CT: Levin, Hugh, and Lauter, http://usmilitary.about.com/library/milinfo/blarguardhistory. htm (Army National Guard history) and http://www.globalse curity.org/military/agency/army/ usar-history.htm (U.S. Army Reserve; accessed March 17, 2009).

[25] Office of Personnel Management. (2009). Nonreduction in pay for certain federal civilian employees on active duty in the uniformed services or National Guard, memorandum for heads of executive departments and agencies. Report No.CPM 2009-07. Washington, DC: Office of the Director, United States Office of Personnel Management.

[26] Orne, G.J., \& Kehoe, E.J. (2012). Perceptions of deployment of Australian Army Reservist by their employers. Military Medicine.
[27] Prati, G, \& Piertrantoni, I. (2010). The relation of perceived social support to mental health among first responders: A meta-analytic review. Journal of Community Psychology, 38 (3), 403-417.

[28] Riviere, L.A., Kendall-Robbins, A., McGurk, D., Castro, C. A. Hoge, C. W. (2011). Coming home may hurt: Risk factors for mental ill health in US reservists after deployment in Iraq. British Journal of Psychiatry, 198 (2), 136-142.

[29] Schumm, W. R., Jurich, A. P., Stever, J. A., Sanders, D., Castelo, C, \& Bollman, S.R. (1998). Attitudes of Reserve component servicemembers regarding the consequences of frequent overseas deployments. Psychological Reports, 83(3, Pt 1), 983-989.

[30] Sortor, R.E., Lippiatt, T.F., Polich, J.M. \& Crowley, J.C. (1994). Training readiness in the Army reserve components. Report No. MR-474-A. Santa Monica: RAND.

[31] U.S. Department of the Army (1997). Institutional leader training and education. TRADOC Regulation 351-10. Fort Monroe, VA: Headquarters, United States Army Training and Doctrine Command.

[32] U.S. Department of Defense. (2008). DoD announces new Reserve component deployment support and reintegration office. News release no. 212-08. Washington, DC: Office of the Assistant Secretary of Defense (Public Affairs.)

[33] U.S. House of Representatives (1993). Title XI, Army National Guard Combat Readiness Reform Act of 1992, October 22, 1992, 106 Stat. 2536. House Report 102-966.

[34] Whitlock, J.E. (2006). How to make Army Force Generation work for the Army reserve component. Carlisle Barracks, PA: Strategic Studies Institute, Army War College.

[35] Wormuth, C.E. (2006). The future of the National Guard and Reserves. Testimony before the Commission on the National Guard and Reserves, June 12, 2006.

[36] Zurcher, L.A. (1977). The Naval reservist: An empirical assessment of ephemeral role enactment. Social Forces, 55 (3), 753-768. 